\title{
Multi-Band Antenna for Different Wireless Applications
}

\author{
H. F. AbuTarboush, H. S. Al-Raweshidy and R. Nilavalan \\ Wireless Networks \& Communications Centre (WNCC) School of Engineering \& Design, Brunel University, West \\ London, $U K$
}

Email: Hattan.AbuTarboush@brunel.ac.uk

\begin{abstract}
A small multi-band compact antenna is presented. The antenna is designed on Roger RT/duroid 5880 with dielectric constant 2.2, multi-band operations is achieved by inserting a slot on the top patch. The antenna has wide impedance bandwidth at 1.2, 1.6, 2.4 and $2.6 \mathrm{GHz}$ with Gain 4.2, 1, 5 and $2 \mathrm{dBi}$ respectively. The bandwidth before adding the shorting wall and the slot was $3.72 \%$, whereas after adding the shorting wall and the slot the bandwidth get wider to $31.9 \%$ at the centre of $1.4 \mathrm{GHz}$. The radiation pattern has acceptable response with low cross polarization at both E-plane and H-plane. The overall dimension of the ground plane is $70 \times 70 \times 1.5 \mathrm{~mm}$.
\end{abstract}

\section{INTRODUCTION}

With the rapid growth of the wireless mobile communication technology, the future technologies needs a very small antenna and also the need of wide band and multi band antenna is increased to avoid using two antennas. Microstrip patch antenna is promising to be a good candidate for the future technology. Microstrip patch antenna consists of a dielectric substrate, with a ground plane on the other side. Due to its advantages such as low weight, low profile planar configuration, low fabrication costs and capability to integrate with microwave integrated circuits technology, the microstrip patch antenna is very well suited for applications such as wireless communications system, cellular phones, pagers, Radar systems and satellite communications systems [1, 2]. Several designs have been investigated and reported to decrease the size of the antenna [3] and to improve the bandwidth of the antenna [4, 5]. Handset antenna has been reported with wide bandwidth [6]. Half U-slot patch antenna with shorting wall reported in [7] with 28\% impedance bandwidth. Recently, three bands WiMAX antenna has been proposed in [8].

In this paper, a compact multiband design of Microstrip patch antenna is proposed. The bandwidth has improved by adding slots and by fine tuning to some parameters to reach the best possible result. The paper divided as follows: section tow, presents the dimensions of the proposed antenna followed by the result of the simulated antenna and the effects of the parameters on the antenna in section three. Finally, section four is conclusion. Results based on a commercially available finite element package HFSS [9].

\section{ANTENNA STRUCTURE}

The geometry and detailed dimensions of the proposed antenna is depicted in fig. 1 and tab. 1. The antenna consists of dielectric substrate and a ground plane. The antenna has tow rectangular patches $17.4 \mathrm{~mm} \mathrm{X} \mathrm{29mm} \mathrm{and} \mathrm{tow} \mathrm{circulars} \mathrm{at}$ the top of the rectangular $\mathrm{R}=8 \mathrm{~mm}$. The antenna is fed by microstrip feeding line with $60 \mathrm{~mm}$ length and $2.5 \mathrm{~mm}$ width, the shorting wall support the stacked patch with the slot at height of $10 \mathrm{~mm}$ above the ground plane. The relative dielectric constant of the Roger RT/duroid 5880 layer is 2.2 and the height (h) is $1.5 \mathrm{~mm}$.

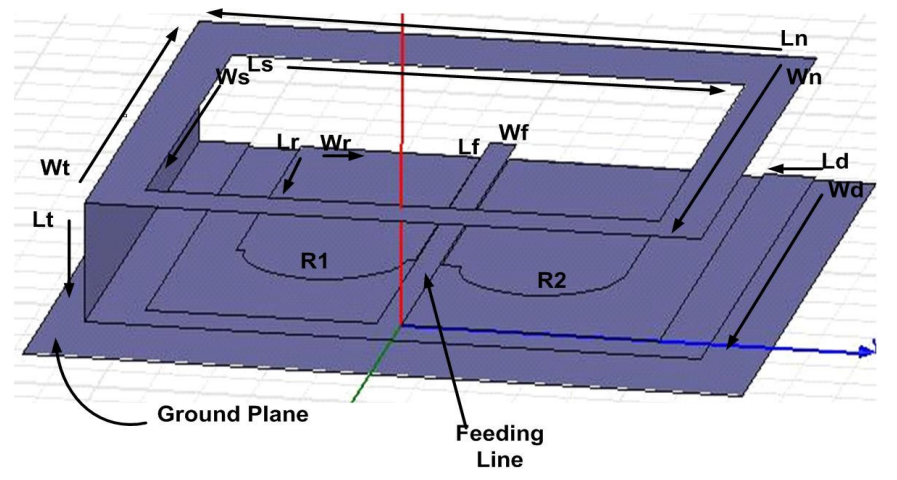

Fig. 1 Geometry of the proposed patch antenna with shorting wall and slot 
Tab. 1 Dimensions of the proposed antenna (Unit: $\mathbf{m m}$ )

\begin{tabular}{|c|c|c|c|c|c|c|c|c|c|c|c|c|c|}
\hline Ws & Ls & Wn & Ln & R1 & R2 & Wr & Lr & Wf & Lf & Wt & Lt & Wd & Ld \\
\hline 45 & 50 & 60 & 60 & 8 & 8 & 17.4 & 29 & 2.5 & 60 & 60 & 10 & 60 & 5 \\
\hline
\end{tabular}

\section{RESULT AND DISCUSSION}

Fig. 2 shows the return loss response of the proposed antenna with shorting wall and stacked slot. The simulated band for $-10 \mathrm{~dB}$ return loss ranges from 1.2 to $1.6 \mathrm{GHz}$, also at $2.4 \mathrm{GHz}$ and at $2.6 \mathrm{GHz}$.

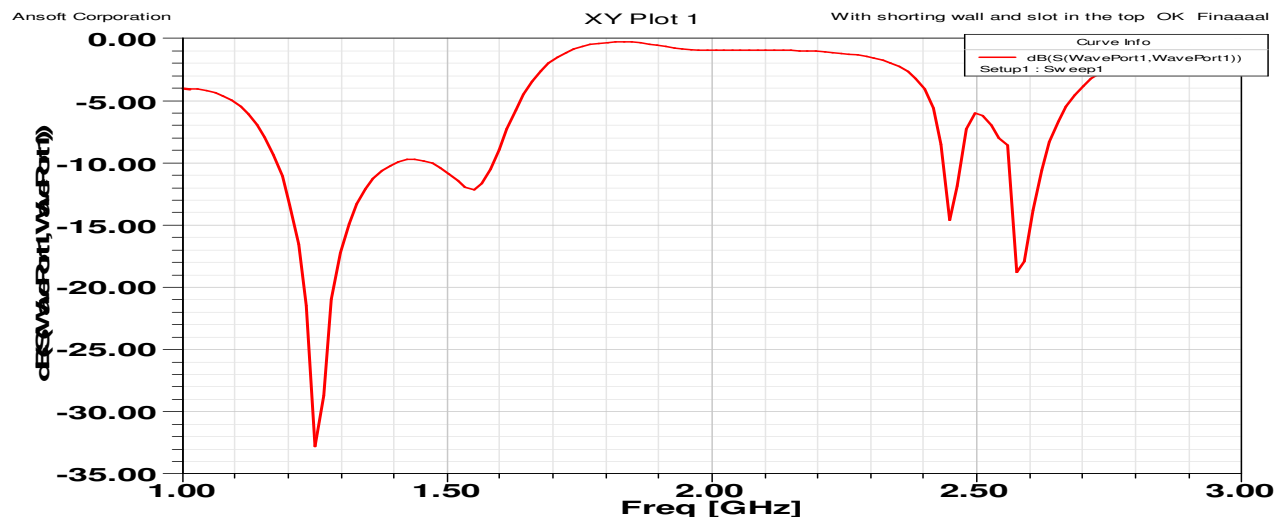

Fig. 2 Return loss response of the proposed antenna.

In order to achieve a wide bandwidth for the proposed antenna a tuning has been done in some parameters.

\section{THE EFFECT OF THE SHORTING WALL}

Fig. 3 shows the effect of the shorting wall and the slot on the bandwidth response, by adding shorting wall and slot, the impedance bandwidth get larger, a parametric study at each parameter have been carried out. The antenna consist of tow rectangular printed on the duroid layer, therefore the fine tuning of the length and width Result in the final targeted frequency band.

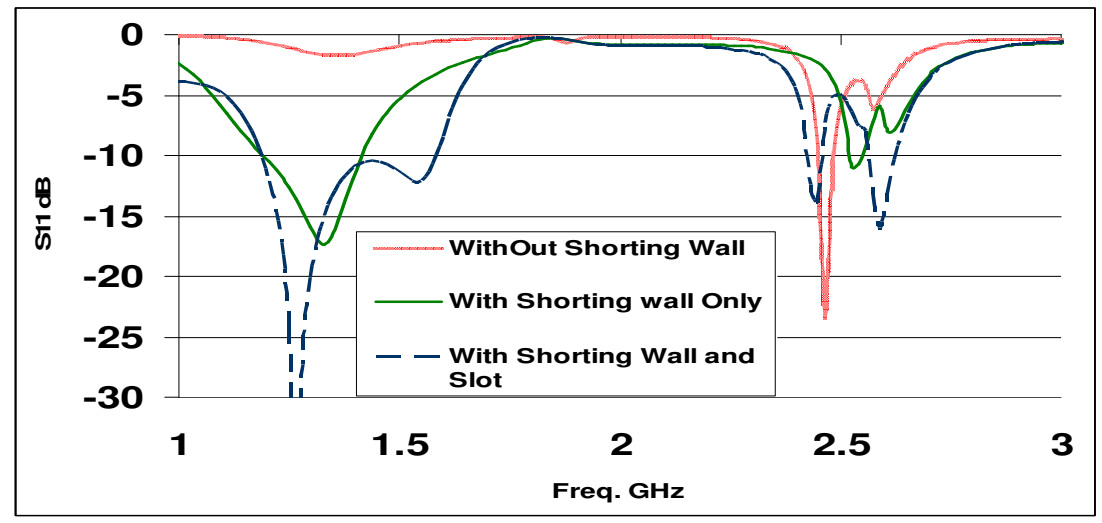

(a)

Fig. 3 The effect of the Shorting wall and the slot 
Radiation pattern for 1.2, 1.6, 2.4 and $2.6 \mathrm{GHz}$ are shown in fig.4 the simulations indicate that for H-Plane radiation pattern, the result present a co polarize radiation below $-10 \mathrm{~dB}$ for all the bands, for E-Plane the result present a cross polarize radiation always below $-15 \mathrm{~dB}$ in all bands.

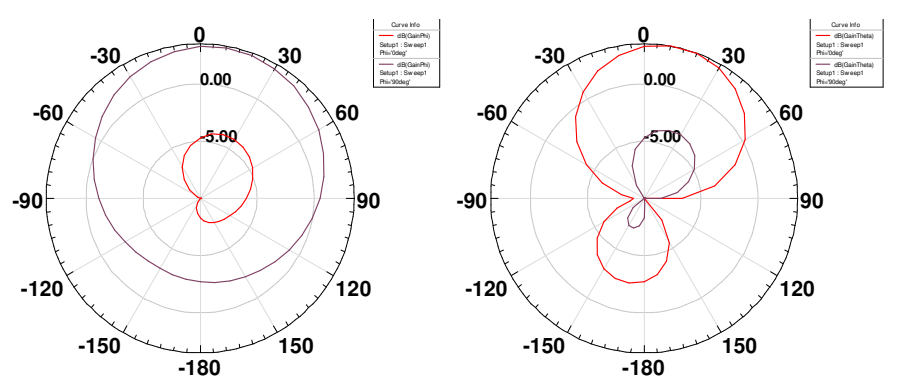

(a)
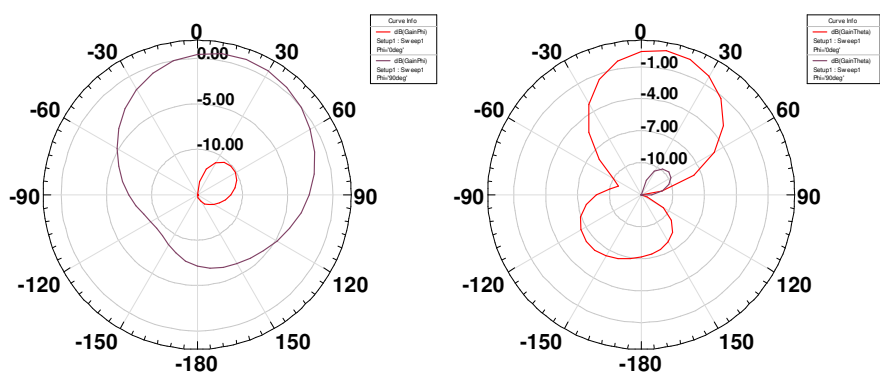

(b)
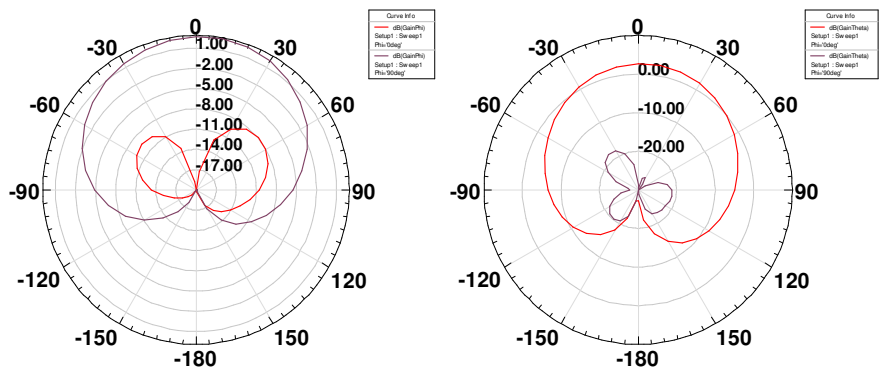

(c)

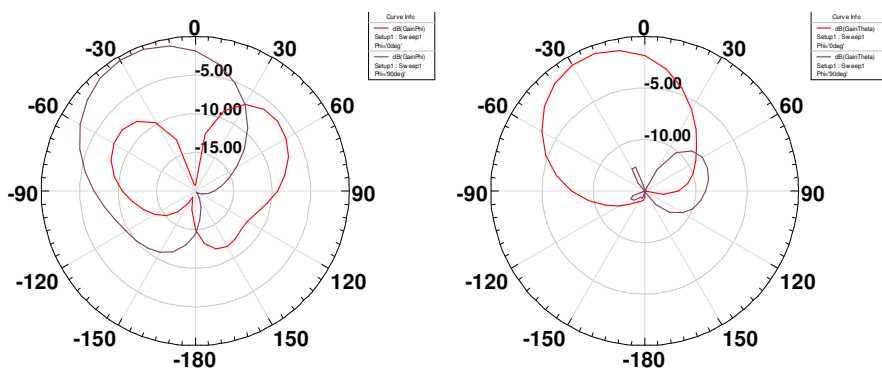

(d)

Fig. 4 Radiation Pattern E-Plane and-H Plane: (a) at $\mathrm{f}=1.18 \mathrm{GHz}$, (b) at $\mathrm{f}=1.62 \mathrm{GHz}$, (c) at $\mathrm{f}=2.4 \mathrm{GHz},(\mathrm{d})$ at $\mathrm{f}=$ 2.6 GHz. 
Tab.2 Max Gains of the proposed Antenna.

\begin{tabular}{|c|c|c|c|c|}
\hline Frequency & $\mathrm{f}=1.18 \mathrm{GHz}$ & $\mathrm{f}=1.62 \mathrm{GHz}$ & $\mathrm{f}=2.4 \mathrm{GHz}$ & $\mathrm{f}=2.6 \mathrm{GHz}$ \\
\hline Max. Gain $(\mathrm{dBi})$ & 4.2 & 1.00 & 2.00 & 5.00 \\
\hline
\end{tabular}

\section{CONCLUSION}

A small multi-band compact antenna with shorting wall and slot on the top patch using microstrip feeding line is presented for 1.2, 1.6, 2.4, 2.6 GHz application. This antenna has a very simple structure printed on a very cheap Duriod substrate for commercial purposes. Wideband has achieved by using a slot on the top patch. The total dimension of the ground plane is $70 \times 70 \mathrm{~mm}$. The antenna characteristic and radiation pattern are satisfactory for most of the wireless system.

\section{REFERENCES}

[1] W.L. Stutzman and G.A. Thiele, Antenna Theory and Design, 2nd ed. New York: Wiley, 1998

[2] C.A. Balanis, Antenna Theory, 2nd ed. New York: John Wiley \& Sons, Inc., 1997.

[3] Nashaat DM, Elsadek H. Miniturized E-shaped dual band PIFA on FR4 substrates. Radio Science Conference, 2006 NRSC 2006 Proceedings of the Twenty Third National. 2006;0:1-6.

[4] FUJIMOTO T. Wideband stacked square microstrip antenna with shorting plates. IEICE Trans B: Communications. 2008 May 1;E91-B(5):1669-72.

[5] Lin S-, Row J-. Bandwidth enhancement for dual-frequency microstrip antenna with conical radiation. Electronics Letters. 2008;44(1):2-3.

[6] Anguera J, Cabedo A, Picher C, Sanz I, Ribo M, Puente C. Multiband handset antennas by means of groundplane modification. Antennas and Propagation International Symposium, 2007 IEEE. 2007:1253-6.

[7] Mak CL, Chair R, Lee KF, Luk KM, Kishk AA. Half U-slot patch antenna with shorting wall. Electronics Letters. 2003;39(25):1779-80.

[8] H. F. AbuTarboush, H. S. Al-Raweshidy, R. Nilavalan, "Triple Band Double U-Slots Patch Antenna for WiMAX Mobile Applications", The 14th Asia-Pacific Conference on Communications (APCC'08), Japan, October 2008.

[9] HFSS, Ansoft Designer, version 11, Ansoft Corporation, UK 